\title{
Familial complex autosomal translocations involving chromosomes 7, 8, and 9 exhibiting male and female transmission with segregation and recombination
}

\author{
S WALKER* $\dagger$, P J HOWARD*, AND D HUNTER \\ From * the Regional Cytogenetics Unit, Royal Liverpool Hospital, PO Box 147, Liverpool L693BX; and $\ddagger$ the \\ Cytogenetics Laboratory, Department of Medical Genetics, St Mary's Hospital, Manchester M13 0JH.
}

SUMmARY A family showing a complex translocation between chromosomes 7,8 , and 9 with breakpoints at 7q21,7q33,8p23, and 9p23 is described. The proband had been referred because of repeated spontaneous abortions. This is only the second family to be ascertained in this way. Twenty-three other cases of complex translocations are briefly reviewed, eight of which were de novo in origin and 15 familial. All but one of the familial cases showed maternal transmission only. The present family shows both maternal and paternal transmission and is thought to be the first exhibiting recombination from a male carrier. The origin and transmission of the complex translocation is followed through three generations.

Complex translocations which may result in the meiotic arrangement of a hexavalent structure imply the involvement of at least three chromosomes from different homologous pairs. Twenty-three such cases $^{1-23}$ have been reported since the advent of chromosomal banding techniques. Reports on persons or families showing independent translocations which allow only up to one or more possible quadrivalent structure at meiosis are excluded.

In the 23 published cases, eight ${ }^{1-8}$ were of de novo origin and $15^{9-23}$ were familial, showing evidence of transmission. Fourteen of the familial cases were maternally transmitted and only one ${ }^{18}$ showed paternal transmission of a complex three chromosome translocation. Crossover products following meiotic pairing were evident in two cases ${ }^{22} 23$ arising from female carriers of the complex translocation.

This paper briefly reviews the 23 reported cases and describes a further family exhibiting complex translocations arising from four breaks between chromosomes 7, 8, and 9 in three generations with both male and female transmission. This case is thought to be the first to show evidence of recombination from a male carrier.

\section{Family history}

The proband (fig 1, III.10) and her husband (III.11) were first referred by the consultant gynaecologist

$\dagger$ Dr Walker has died since this paper was submitted.

Received for publication 10 June 1985

Accepted for publication 26 June 1985. for cytogenetic studies when 31 and 34 years of age $\vec{\bullet}$ respectively. At that time there had been eighe of pregnancies between them resulting in six spons taneous abortions and only two living, apparentle normal, female children (IV.8, IV.12). The abor:tions had all occurred in the first trimester and suggested a possible chromosomal problem as there was no evidence of any mechanical abnormality of the uterus or any other underlying disease. The proband informed the gynaecologist that her mother had also had recurrent abortions.

Chromosomal analysis on the first specimens of blood received showed that whereas her husband had a normal karyotype, the proband had a complex translocation karyotype. There was clear evidence of one normal chromosome 7 and a deleted $7 q$ with the $q$ arm translocated onto one 9p. The terminal bands of the translocation $7 \mathrm{q}$ arm $(7 \mathrm{q} 33 \rightarrow 7 \mathrm{qter})$ appeared absent, however, and one $8 \mathrm{p}$ arm was longer than its partner. This was confirmed by a further blood specimen and clarified by evidence obtained from blood specimens from the parents (II.2, II.3) of the proband. Whereas the mother had a normal karyotype, the father exhibited a different balanced arrangement from that seen in his daughter with two reciprocal translocations, $t(7 q ; 9 p)$ and $t(7 q ; 8 p)$, involving both homologues of chromosome 7 . Appropriate genetic counselling was given.

The pedigree (fig 1) shows those members of the family who have since been investigated. These include the only other surviving member in genera- 


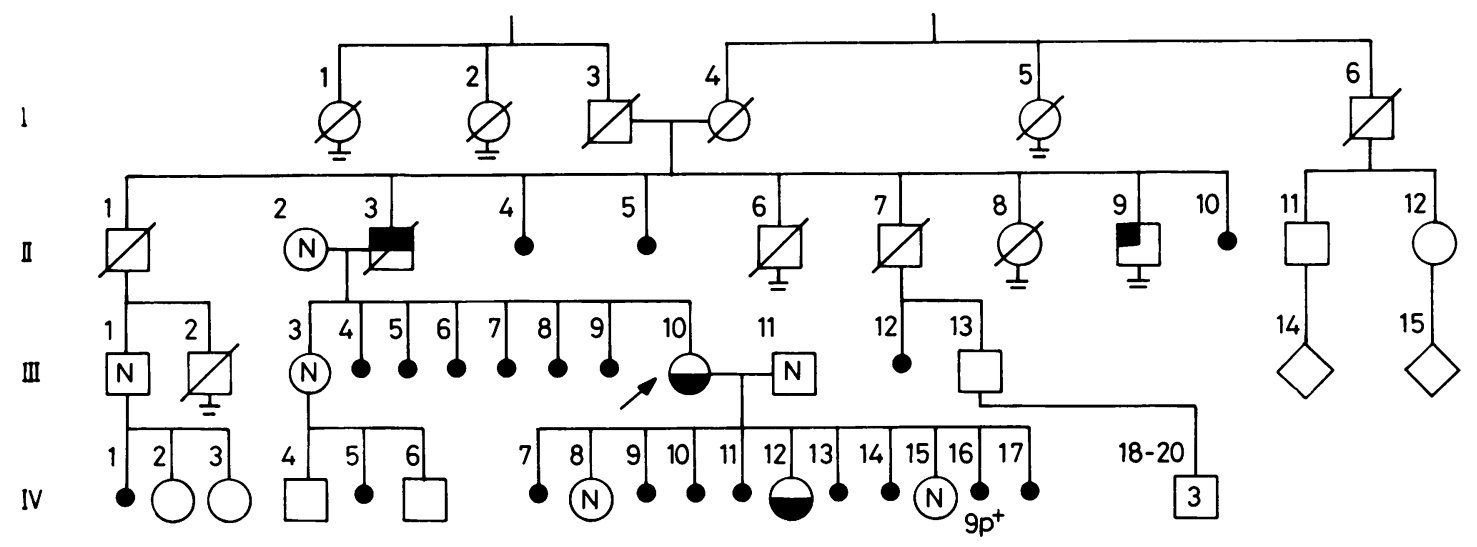

\begin{tabular}{|llll|}
\hline$\square$ & Dead & $\bigcirc$ & Unknown sex \\
$\mathrm{N}$ & Normal karyotype & $\bullet$ & Spontaneous abortion \\
& Balanced $\mathrm{t}(7 \mathrm{q} ; 8 \mathrm{p})$ & $\bullet$ & Spontaneous abortion, \\
& Balanced $\mathrm{t}(7 \mathrm{q} ; 8 \mathrm{p}), \mathrm{t}(7 \mathrm{q} ; 9 \mathrm{p})$ & $9 \mathrm{p}^{+}$ & unbalanced $\mathrm{t}(7 \mathrm{q} ; 8 \mathrm{p} ; 9 \mathrm{p})$ \\
& Balanced $\mathrm{t}(7 \mathrm{q} ; 8 \mathrm{p} ; 9 \mathrm{p})$ & $\underline{1}$ & No offspring \\
& Proband & & \\
\hline
\end{tabular}

FIG 1 Family pedigree showing the occurrence and transmission through recombination and segregation of the translocations $t(7 q ; 8 p)$ and $t(7 q ; 9 p)$. Descendants of 1.6 and 11.7 were not available for cytogenetic study. See text for details.

tion II (II.9, uncle of the proband) who carries a single translocation, $t(7 q ; 8 p)$, a sister (III. 3 ) and cousin (III.1) of the proband (each with a normal karyotype), and the three female children of the proband (IV.8, IV.12, IV.15). The daughters IV.8 and IV.15 have normal karyotypes while daughter IV.12 is a balanced complex translocation carrier with the same arrangement as seen in the proband. Amniocentesis was performed for IV.15 and the pregnancy was allowed to continue, but two further pregnancies ended in early abortion. Tissue from IV.16 showed the conceptual products to be genetically unbalanced with a 9p+, but the following abortus (IV.17) was in a macerated condition and was unsuitable for cytogenetic analysis. Histology of irregular fragments of the fetus and of irregular pieces of placenta did not reveal any significant abnormalities.

Two branches of the family arising from members I.6 and II.7 were unavailable for investigation as they lived in America and Canada respectively and were no longer in contact with other family members.

\section{Cytogenetic studies}

As the family lives in different areas of the northwest, collaboration between Liverpool Regional Cytogenetics Unit and Manchester (St Mary's Hospital) Cytogenetics Laboratory was arranged. Blood specimens from the proband (fig 1, III.10), her husband (III.11), her sister (III.3), and her two daughters (IV.8, IV.12), and the amniotic fluid from IV.15 were examined in Liverpool. Blood specimens from family members II.2, II.3, II.9, and III.1, together with the products of conception from the pregnancy IV.16, were investigated in Manchester. Trypsin-Giemsa banding of chromosomes was carried out on all specimens. Details of chromosomes 7,8 , and 9 in all relevant family members are shown in fig 2 and the positions of the translocation breakpoints in fig 3 .

The father of the proband (II.3, now dead) was found to have two reciprocal translocations arising from four breaks involving both homologues of chromosome 7 and one of each chromosome 8 and 9. He had a chromosomal complement of 

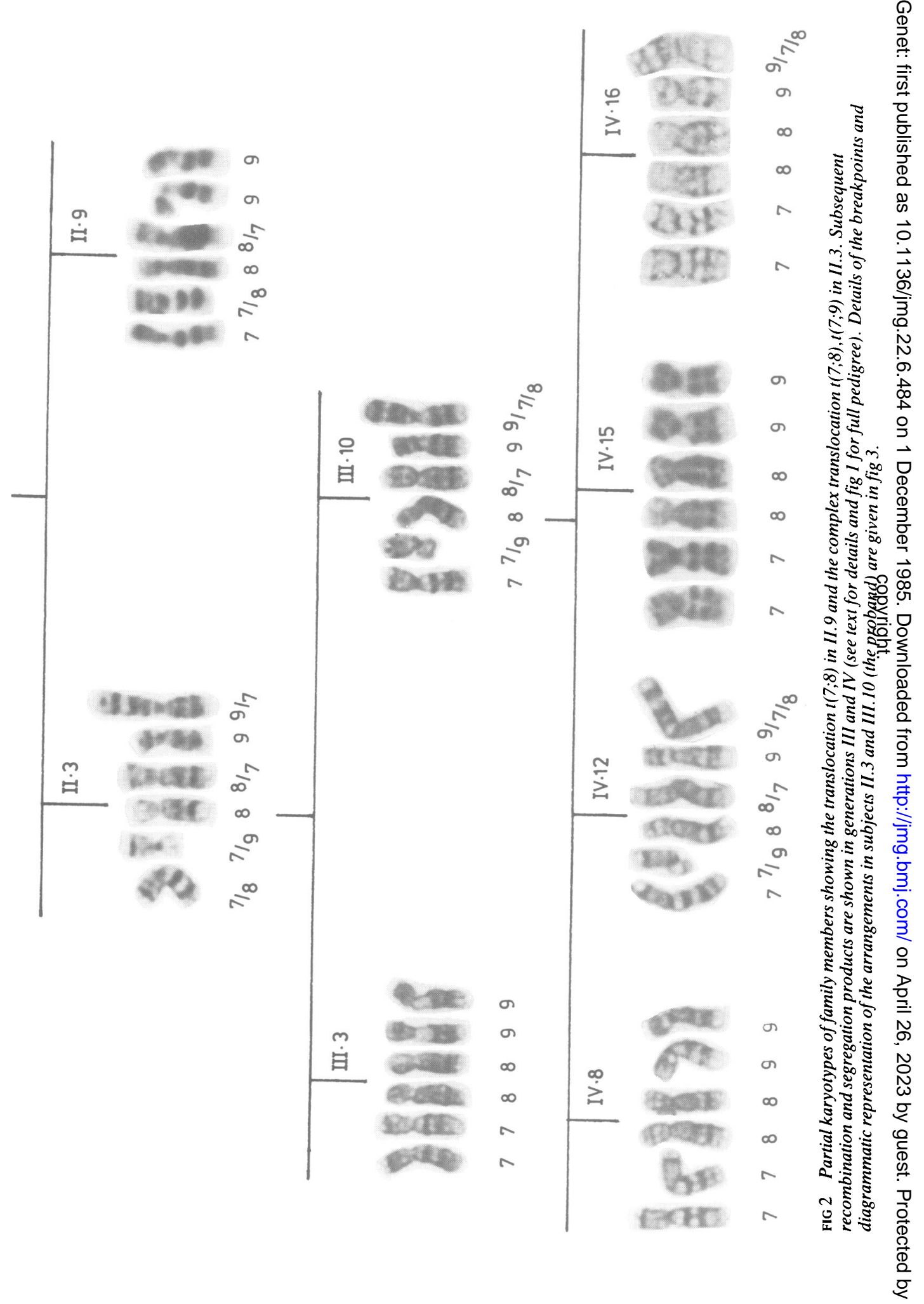


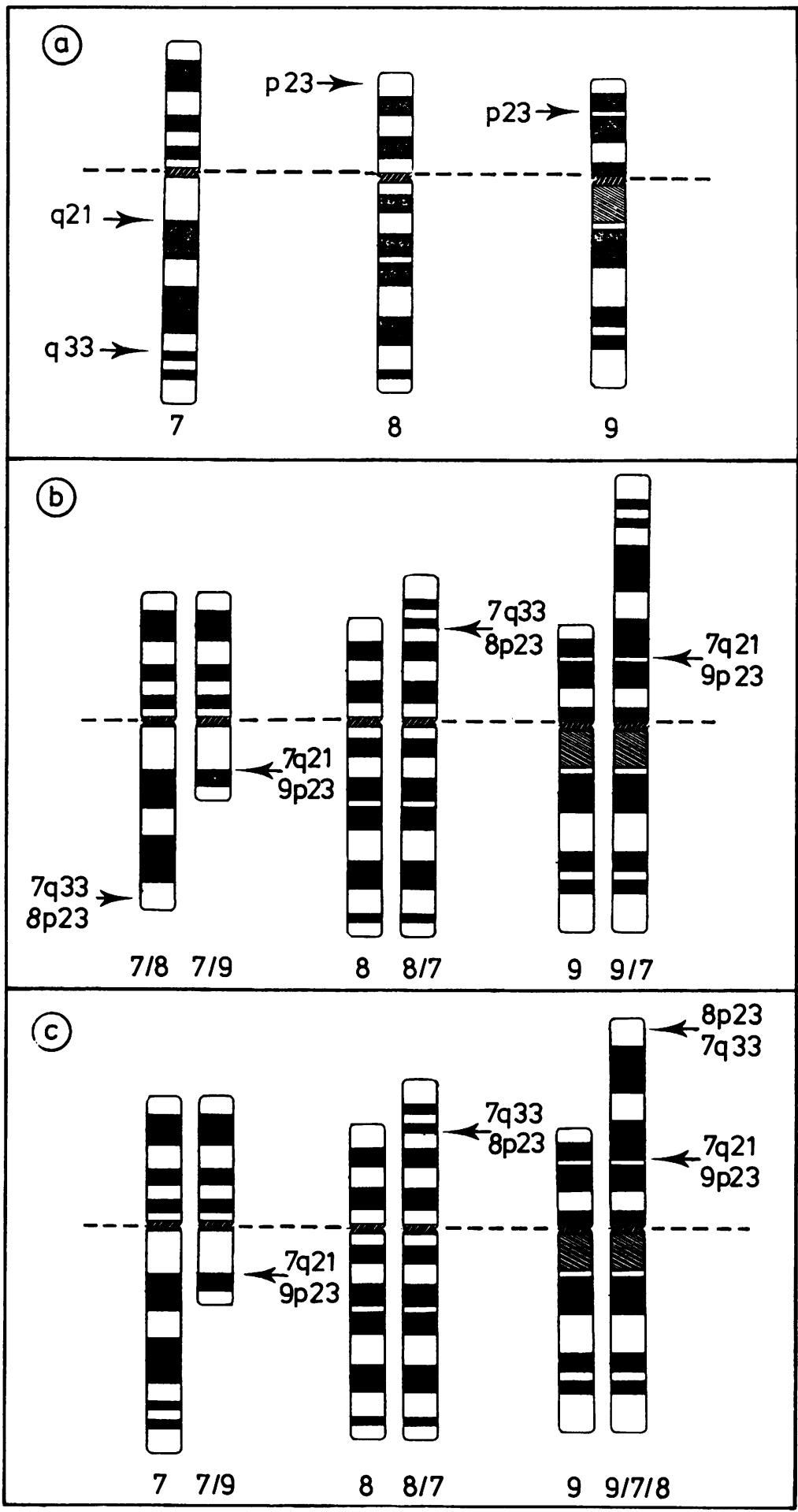

FIG 3 Diagrammatic representation of chromosomes 7 , 8 , and 9 and the complex translocations seen in the family. (a) Chromosomes 7, 8, and 9 showing the breakpoints involved. (b) Complex translocation between chromosomes 7,8 , and 9 present in II.3 (see fig 2). (c) Complex translocation between chromosomes 7,8 , and 9 present in III.10 (see fig 2). 
$46, X Y, t(7 ; 8)(q 33 ; p 23), t(7 ; 9)(q 21 ; p 23)$ which was balanced and would probably have given rise to a hexavalent configuration (ring or chain) during meiotic pairing. His only living sib, a brother (II.9), carries a single reciprocal translocation between chromosomes 7 and 8 with a complement of $46, X Y, t(7 ; 8)(q 33 ; p 23)$.

The proband (III.10) and her sister (III.3) both show recombination products in their chromosomal complements. The sister has a normal chromosomal complement $(46, \mathrm{XX}, \mathrm{rec}(7)$ pat $)$, having obtained through recombination a normal chromosome 7 as well as normal chromosomes 8 and 9 from her father. The proband has received a derived 7 , a derived 8 , and a recombination 9 from her father, such that her chromosomal complement is $46, \mathrm{XX}$, $-7,-8,-9,+\operatorname{der}(7), \mathrm{t}(7 ; 9)(\mathrm{q} 21 ; \mathrm{p} 23) \mathrm{pat},+\operatorname{der}(8), \mathrm{t}(7 ;$ 8)(q33;p23)pat, +rec(9),t(7;8),t(7;9)(q21q33;p23;p23) pat. The recombination chromosome 9 involved all three chromosomes in the arrangement $t(7 ; 8 ; 9)$ $(9 \mathrm{qter} \rightarrow 9 \mathrm{p} 23:: 7 \mathrm{q} 21 \rightarrow 7 \mathrm{q} 33:: 8 \mathrm{p} 23 \rightarrow 8$ pter $)$.

Two (IV.8, IV.15) of the three daughters of the proband have normal chromosomal complements $(46, \mathrm{XX})$, while the third daughter (IV.12) has the same balanced complex chromosomal translocation as her mother. The products of conception from abortus IV.16 showed an unbalanced chromosomal arrangement with $46, \mathrm{XY},-9, \operatorname{der}(9)$ mat. The abortus was therefore trisomic for $7 \mathrm{q} 21 \rightarrow 7 \mathrm{q} 33$, trisomic for $8 \mathrm{p} 23 \rightarrow 8 \mathrm{pter}$, and monosomic for $9 \mathrm{p} 23 \rightarrow 9$ pter.
The only cousin (fig 1, III.1) of the proband available for cytogenetic investigation has a normal chromosomal complement $(46, X Y)$.

\section{Discussion}

The finding of complex translocations in the general population is rare, but the frequency of occurrence is probably much higher, many remaining undetected due to the lack of clinical or phenotypic effects when in the balanced state. Ascertainment (table 1) of the eight de novo cases has been through children with dysmorphic features and mental retardation associated with small chromosomal deletions, ${ }^{38}$ or an apparently balanced karyotype,${ }^{146}$ or through adult males exhibiting infertility. ${ }^{2} 57$ In the cases showing familial transmission $^{9-23}$ and the present report, only two of the 16 families were ascertained through repeated abortions (reference 22 and the present case). One case $^{11}$ was ascertained through a single abortus investigated in a survey of spontaneous abortions and found to have an unbalanced karyotype. The 13 others $^{9} 10^{12-21} 23$ were ascertained through an abnormal child, each having a partial trisomy due to unbalanced segregation of the complex translocation. On investigation, a further two of these families ${ }^{1012}$ also showed evidence of frequent miscarriages. The frequency of recurrent abortions seen from parental carriers of complex translocations

TABLE 1 Ascertainment of cases exhibiting complex translocations.

\begin{tabular}{|c|c|c|c|c|c|c|}
\hline \multirow[t]{2}{*}{ Reference } & \multirow{2}{*}{$\begin{array}{l}\text { Chromosomes } \\
\text { involved }\end{array}$} & \multirow{2}{*}{$\begin{array}{l}\text { Familiall } \\
\text { de novo }\end{array}$} & \multicolumn{4}{|c|}{ Ascertainment through } \\
\hline & & & $\begin{array}{l}\text { Spont } \\
\text { Aborts }\end{array}$ & $\begin{array}{l}\text { Abnormal } \\
\text { child (sex) }\end{array}$ & & $\begin{array}{l}\text { Male } \\
\text { infertility }\end{array}$ \\
\hline 1 & 1.5 .9 & DN & & Mildly dysmorphic & $(\mathrm{F})$ & \\
\hline 2 & 4.7 .15 & DN & & - & - & Subfertile \\
\hline 3 & $3.11,14$ & DN & & Interst del $14 q$ & (M) & \\
\hline 4 & $3.7 .21 . \mathrm{X}$ & DN & & Retardation/dysmorphic & (F) & \\
\hline 5 & $11,12.21$ & DN & & - & - & Azoospermic \\
\hline 6 & $2,4,7,8$ & DN & & Mild mental retardation & $(\mathrm{M})$ & \\
\hline 7 & $1,5,10,12$ & DN & & - & - & Azoospermic \\
\hline 8 & 1.8 .14 & DN & & Interst del $8 q$ & $(\mathrm{M})$ & \\
\hline 9 & 6.14 .20 & Fam & & Partial trisomy $14 q$ & (F) & \\
\hline 10 & 5.7 .17 & Fam & & Partial trisomy $7 q$ & (M) & \\
\hline 11 & $3,4,14$ & Fam & + & - & (M) & \\
\hline 12 & $9,13,14$ & Fam & & Trisomy $9 p$ & (M) & \\
\hline 13 & $11,12,13$ & Fam & & Partial trisomy $11 \mathrm{p}$ & (F) & \\
\hline 14 & 7.11 .21 & Fam & & Translocation trisomy 21 & (F) & \\
\hline 15 & 9.21 .22 & Fam & & Trisomy $9 p$ & (M) & \\
\hline 17 & 4.6 .9 & Fam & & Partial trisomy $9 p$ & (F) & \\
\hline 18 & $6.10,13$ & Fam & & Partial trisomy $13 \mathrm{q}$ & (F) & \\
\hline 19 & $1,5,6$ & Fam & & Partial trisomy lq & (M) & \\
\hline 20 & $1,8.15$ & Fam & & Partial trisomy $8 \mathrm{q}$ & (F) & \\
\hline 21 & $2,3,13$ & Fam & & Partial trisomy $13 \mathrm{q}$ & (M) & \\
\hline 22 & 5.7 .12 & Fam & ++++ & - & - & \\
\hline 23 & $1,6,7$ & Fam & & Partial trisomy $7 q$ & (M) & \\
\hline Present case & 7.8 .9 & Fam & +++++ & - & - & \\
\hline
\end{tabular}


appears lower than might be expected in such families.

Within the progeny cytogenetically examined from the 16 carrier families are seven (five female, two male) with a normal karyotype, 13 (10 female, three male) with a balanced karyotype and 14 (eight female, six male) with an unbalanced karyotype. Although numbers are low, there is an apparent excess of female offspring, particularly with a normal or balanced karyotype. The ratio of balanced to unbalanced offspring is, however, approximately unity. The majority of the familial cases $^{9-17}{ }^{19-23}$ show the complex translocation to have been maternally transmitted. This, however, may be the result of biased ascertainment, as male carriers may be less likely to produce unbalanced progen $y^{24}$ or may be infertile. ${ }^{2}$ The three reported de novo cases of complex translocations in adult men ${ }^{25}$ show either azoospermia or subfertility. Only two cases (reference 18 and the present case) show paternal transmission of a complex translocation. Neither of the fathers in these families suggests any reduction in ability to effect fertilisation, though in the present case six of the eight pregnancies from the male carrier (fig 1, II.3) resulted in early abortions.

Previous reports ${ }^{32}$ have commented upon the frequency of specific chromosomes involved in complex translocations. Only 12 of the combined 20 cases reported then meet the criteria for inclusion here, and the frequency of chromosome involvement seen in the 24 cases referred to here is shown in table 2. Chromosome 7 is involved most frequently. In the present family chromosomes 7,8 , and 9 are involved. The breakpoints which have been recorded in these three chromosomes when found in complex translocations are given in table 3 and suggest a non-random distribution.

Cytogenetic study of the present family has shown both segregation and recombination of the complex translocation arrangement (fig 2). Diagrammatic representation of the translocations in the male carrier (II.3) and the recombination product in his

TABLE 2 Frequency of chromosome involvement in complex translocations.

\begin{tabular}{ll}
\hline No of times involved & Chromosomes involved in complex translocations \\
\hline 0 & $16,18,19, \mathrm{Y}$ \\
1 & $17,22, \mathrm{X}$ \\
2 & $2,10,15,20$ \\
3 & - \\
4 & $4,8,12,13,21$ \\
5 & $3,5,6,9,11,14$ \\
6 & 1 \\
7 & 7 \\
8 & 7 \\
\hline
\end{tabular}

TABLE 3 Breakpoints identified in complex translocations involving chromosomes 7,8 , and 9.

\begin{tabular}{|c|c|c|c|c|}
\hline \multirow[t]{2}{*}{ Ref } & \multirow{2}{*}{$\begin{array}{l}\text { Chromosomes } \\
\text { involved }\end{array}$} & \multicolumn{3}{|c|}{ Breakpoints } \\
\hline & & 7 & 8 & 9 \\
\hline 1 & 1.5 .9 & & & $\mathrm{p} 21$ \\
\hline 2 & 4.7 .15 & $\mathrm{q} 22$ & & \\
\hline 4 & $3, \overline{7}, 21, \mathrm{X}$ & $\begin{array}{l}\text { p12 } \\
\text { q21 }\end{array}$ & & \\
\hline 6 & $2,4, \underline{7}, \underline{8}$ & q11 & $\mathrm{q} 13$ & \\
\hline 8 & $1,8,14$ & & $\begin{array}{l}\mathrm{p} 23 \\
\mathrm{q} 24\end{array}$ & \\
\hline 10 & $5.7,17$ & $\begin{array}{l}\mathrm{q} 22 \\
\mathrm{q} 32\end{array}$ & & \\
\hline 12 & $9.13,14$ & & & q12 \\
\hline 14 & $\underline{\overline{7}} .11 .21$ & p22 & & \\
\hline 15 & $\frac{1}{9} .21 .22$ & & & q12 \\
\hline 17 & 4.6 .9 & & & $\mathrm{pl}$ \\
\hline 20 & 1.8 .15 & & $\mathrm{q} 22$ & \\
\hline 22 & $5,7,12$ & p14 & & \\
\hline 23 & $1,6,7$ & q32 & & \\
\hline Present case & 7.8..$\overline{9}$ & $\begin{array}{l}\text { q21 } \\
\text { q33 }\end{array}$ & $\mathrm{p} 23$ & p23 \\
\hline
\end{tabular}

daughter (III.10) is shown in fig 3. The possible hexavalent pairing arrangements in II. 3 and III. 10 at pachytene of meiosis is shown in fig 4 , giving rise to either a ring or chain structure at diakinesis. Only crossing over in the differential segment would be cytologically recognisable in conceptual products. Crossover in the terminal or interstitial segments could not be recognised. Both offspring (III.3, III.10) of the male carrier II.3 show evidence of recombination following crossing over in the differential segment and adjacent 1 (non-homologous) segregation, whereas the three offspring (IV.8, IV.12, IV.15) of the female carrier III.10 show evidence of alternate segregation, and the unbalanced products of conception (IV.16) adjacent 1 segregation but not recombination. Two previous reports ${ }^{22}$ also show evidence of recombination in complex translocations but resulting from female carriers. One of these female carriers ${ }^{23}$ with a complex translocation involving chromosomes 1,6 , and 7 produced two balanced offspring after recombination, one unbalanced (partial trisomy $7 q$ ) through malsegregation, and only a single miscarriage. The other ${ }^{22}$ presented as a case with five recurrent abortions and one apparently normal child who was found to have a single balanced translocation after recombination from a complex translocation involving chromosomes 5, 7, and 12 .

The frequent early abortions from translocation carriers in the present family (fig 1) are most probably due to malsegregation of the complex arrangement during meiosis, although proof of this is limited to the investigation of the abortus IV.16. If 
(a) Subject III.3

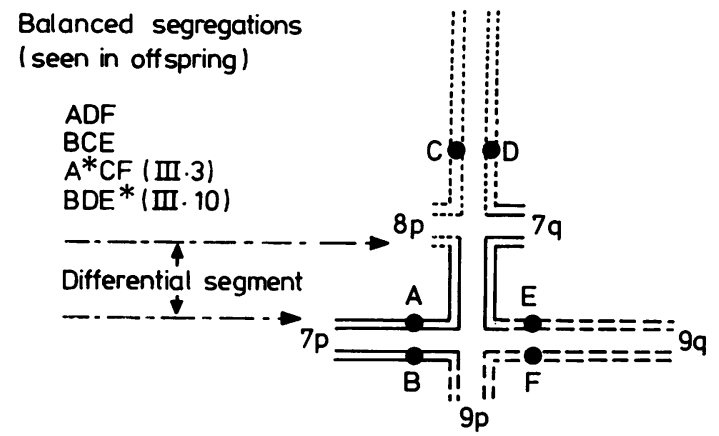

(b) Subject III.10

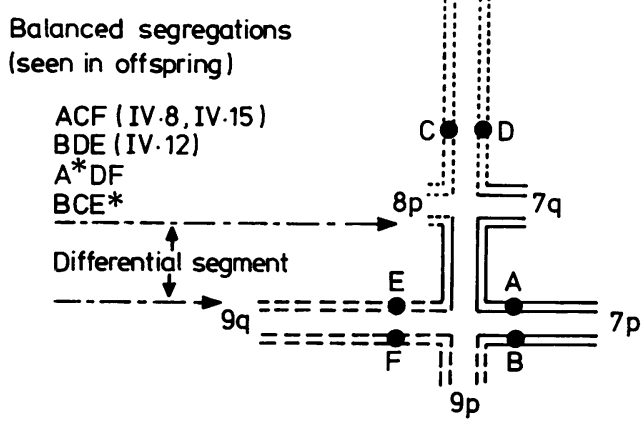

FIG 4 Possible pachytene configurations of the complex translocations seen in (a) II.3 and (b) III.10. A/B, C/D, and $E / F$ are the homologous pairs of centromeres of chromosomes 7,8 , and 9 respectively. ${ }^{*}$ Denotes the centromere $\left(A^{*}\right.$ or $\left.E^{*}\right)$ attached to the chromosome involved in a single crossover in the differential segment.

segregation of the meiotic configuration is considered with and without a single crossover in the differential segment, then there are 16 possible arrangments. Only four of these (two crossovers and two non-crossovers) would be balanced (fig 4). In this family, therefore, the theoretical estimate for the expected frequency of balanced and unbalanced products of conception corresponds closely to the actual outcome, assuming the abortions were unbalanced.

The origin of the complex translocation in this family must have occurred in subject II.3. This male carrier possesses two translocated chromosomes 7 with $t(7 q ; 8 p)$ and $t(7 q ; 9 p)$. Investigation of his only surviving sib (II.9) shows the presence of $t(7 q ; 8 p)$ and hence this translocation must have been transmitted from one of the parents I.3 or I.4 (both dead). Investigation of the only other surviving relative in a different branch of the family (nephew III.1) did not reveal any translocation. The translocation $t(7 q ; 9 p)$ must therefore have either been transmitted from one of the parents I.3 or I.4 (but not the one with the translocation $t(7 q ; 8 p))$ or have arisen de novo at the time of conception of II.3.

Genetic counselling in families of this kind is obviously strongly advisable, with the offer of cytogenetic prenatal diagnosis in pregnancies of translocation carriers. The degree of risk for a pregnancy with an unbalanced zygote to go to term is much reduced in those families showing repeated abortions (reference 22 and present case) but may be high in others when ascertained through unbalanced progeny.

We wish to thank Mr J F B Clarke, Consultant Gynaecologist and Obstetrician, Chorley and District Hospital, for the original referral and close collaboration in the follow up of the proband during her last three pregnancies. Thanks are also due to Mrs N Charles (Manchester) for the collection of blood specimens and additional pedigree data from part of the family, and to Mrs A Satchwell (Liverpool) for cytogenetic technical assistance.

\section{Addendum}

Since this paper was submitted, a further case ${ }^{25}$ of de novo rearrangement involving chromosomes 1,7 13 , and $\mathrm{X}$ has been drawn to the attention of the authors.

\section{References}

1 Martinetti J, Noel B. Remaniement complexe de novo touchan quatre chromosomes chez un nouveau-né. Ann Genet (Paris) 1973;16:285-8.

2 Chandley $\mathrm{AC}$, Edmond $\mathrm{P}$, Christie S, et al. Cytogenetics and infertility in man. Ann Hum Genet 1975;39:231-54.

${ }^{3}$ Buchanan PD, Rao KW, Doerr CL, Aylsworth AS. A complex translocation involving chromosomes 3,11 and 14 with an interstitial deletion, $\operatorname{del}(14)(\mathrm{q} 13 \mathrm{q} 22)$, in a child with congenita glaucoma and cleft lip and palate. Birth Defects 1978;14:317-22.

4 Pai GS, Thomas GH, Mahoney W, Migeon BR. Complex chromosome rearrangements. Report of a new case and literature review. Clin Genet 1980;18:436-44.

5 Joseph A, Thomas IM. A complex rearrangement involving three autosomes in a phenotypically normal male presenting with sterility. J Med Genet 1982;19:375-7.

${ }^{6}$ Couzin DA, Watt JL, Auchterlonie IA. A complex double translocation involving four chromosomes and five breakpoints in a child with mild mental retardation. $J$ Med Genet 1983;20:389-92.

${ }^{7}$ Rodriguez MT, Martin MJ, Abrisqueta JA. A complex balanced rearrangement involving four chromosomes in an azoospermic man. J Med Genet 1985;22:66-7.

* Schwartz S, Beisel JH, Panny SR, Cohen MM. A complex rearrangement, including a deleted $8 \mathrm{q}$, in a case of LangerGiedion syndrome. Clin Genet 1985;27:175-82.

9 Allerdice PW, Miller OJ, Miller DA. Familial translocation 
involving chromosomes 6,14 and 20 identified by quinacrine fluorescence. Humangenetik 1971:13:205-9.

${ }^{10}$ Berger R, Derre J, Ortiz MA. Les trisomies partielles du bras long du chromosome 7. Nouv Presse Med 1974:3:1801-4

1 Creasy MR, Crolla JA, Daker MG. A familial reciprocal translocation between three chromosomes. Humangenetik 1974;24:303-8.

${ }^{12}$ Fujita H, Abe T, Yamamoto K, Furuyana J. Possible complex translocation $\mathrm{t}(9 ; 14 ; 13)(\mathrm{q} 12 ; \mathrm{p} 1$ ?; $; 31)$ in mother of a child with 9p trisomy syndrome. Humangenetik 1974:25:83-92.

${ }^{13}$ Sanchez O, Yunis JJ, Escobar JI. Partial trisomy 11 in a child resulting from a complex maternal rearrangement of chromosomes 11, 12 and 13. Humangenetik 1974;22:59-65.

${ }^{14}$ Schwinger E, Mikkelsen M, Niesen M. Familial balanced $(7 ; 11 ; 21)$ translocation and Down's syndrome in two siblings. Clin Genet 1975;7:304-7.

15 Dallapiccola B, Bollea G, Mazzilli C, Gandini E. Complex translocation $\mathrm{t}(9 ; 21)(9 ; 22)(\mathrm{q} 12 \mathrm{p} 13)(\mathrm{q} 12 \mathrm{q} 11)$ in the family of a child with 9p trisomy syndrome. Hum Genet 1976;33:73-6.

${ }^{16}$ Palmer CG, Poland C, Reed T, Kojetin J. Partial trisomy 11, $46, X X,-3,-20,+\operatorname{der} 3,+\operatorname{der} 20, t(3,11,20)$ resulting from a complex maternal rearrangement of chromosomes $3,11,20$. Hum Genet 1976;31:219-25.

17 Tanaka N, Ikeuchi T, Yara I, Kitihara K. Trisomy 9p due to a maternal complex translocation involving chromosomes 4, 6 and 9. Jpn J Hum Genet 1977;21:261-8.

${ }^{18}$ Schwanitz G, Schmid P, Berthold HJ, Grosse KP. Partial trisomy 13 with clinical signs of Patau syndrome resulting from a complex paternal rearrangement of chromosomes 6,10 and 13 . Ann Genet (Paris) 1978;21:100-3.
${ }^{19}$ Hustinx TWJ, Nabben FAE, Scheres JMJC. Partial trisomy of chromosome 1 resulting from a complex maternal rearrangement of chromosomes 1,5 and 6. Am J Med Genet 1979:3: 353-8.

${ }^{20}$ Ballesta F, Fernández E, Milá $M$. Translocation $t(1 ; 8 ; 15)$ maternelle et trisomie 8qter chez la fille. J Genet Hum 1980;28:361-6.

${ }^{21}$ Muneer RS, Donaldson DL, Rennert OM. Complex balanced translocation of chromosomes 2, 3 and 13. Hum Genet 1981;59:182-4.

22 Tabor A, Jensen LK, Lundsteen C, Niebuhr E. A 5;7, 5;12 double reciprocal translocation in a normal mother and a $5 ; 7$ translocation with a recombinant chromosome 5 in her normal child. J Med Genet 1981;18:307-9.

${ }^{23}$ Bass HN, Sparkes RS, Lessner MM, Fox M, Phoenix B, Bernar J. A family with three independent autosomal translocations associated with $7 \mathrm{q} 32 \rightarrow 7 \mathrm{qter}$ syndrome. J Med Genet 1985;22:59-63.

24 Hamerton JL. Human cytogenetics. In: General cytogenetics. Vol 1. New York, London: Academic Press, 1971.

25 Seabright M. Gregson N. Pacifico E. et al. Rearrangements involving four chromosomes in a child with congenital abnormalities. Cytogenet Cell Genet 1978;20:150-4.

Correspondence and requests for reprints to $\mathbf{P} \mathbf{J}$ Howard, Cytogenetics Unit, Royal Liverpool Hospital, PO Box 147, Liverpool L69 3BX. 